\title{
Evaluating Assisted Gene Flow in Marginal Populations of a High Mountain Species
}

\author{
Samuel Prieto-Benítez 1,2*, Javier Morente-López 2,3, María Luisa Rubio Teso², \\ Carlos Lara-Romero ${ }^{2,4}$, Alfredo García-Fernández ${ }^{2}$, Elena Torres ${ }^{5}$ and \\ José María Iriondo ${ }^{2}$
}

\begin{abstract}
${ }^{1}$ Ecotoxicology of Air Pollution Group, Environmental Department, Centro de Investigaciones Energéticas, Medioambientales y Tecnológicas (CIEMAT), Madrid, Spain, ²Área de Biodiversidad y Conservación, Departamento de Biología y Geología, Física y Química Inorgánica, Escuela Superior de Ciencias Experimentales y Tecnología (ESCET), Universidad Rey Juan Carlos, Móstoles, Spain, ${ }^{3}$ Department of Botany, Ecology, and Plant Physiology, University of La Laguna, La Laguna, Spain, ${ }^{4}$ Ecology Area, Life Science Department, University of Alcalá (UAH), Alcalá de Henares, Spain, ${ }^{5}$ Departamento de Biología Vegetal, Universidad Politécnica de Madrid, Ciudad Universitaria, Madrid, Spain
\end{abstract}

\section{OPEN ACCESS}

Edited by:

Domenico Gargano, University of Calabria, Italy

Reviewed by:

Marta Barberis,

University of Bologna, Italy

Thomas Abeli,

Roma Tre University, Italy

*Correspondence:

Samuel Prieto-Benítez

samuelonbio@gmail.com;

samuel.prieto@urjc.es

Specialty section:

This article was submitted to Evolutionary and Population Genetics,

a section of the journal

Frontiers in Ecology and Evolution

Received: 09 December 2020 Accepted: 07 May 2021

Published: 07 June 2021

Citation:

Prieto-Benitez S,

Morente-López J, Rubio Teso ML, Lara-Romero C, García-Fernández A,

Torres $E$ and Iriondo JM (2021)

Evaluating Assisted Gene Flow

in Marginal Populations of a High

Mountain Species.

Front. Ecol. Evol. 9:638837.

doi: 10.3389/fevo.2021.638837
Many species cannot either migrate or adapt at the rate of temperature increases due to climate warming. Therefore, they need active conservation strategies to avoid extinction. Facilitated adaptation actions, such assisted gene flow, aim at the increase of the evolutionary resilience of species affected by global change. In elevational gradients, marginal populations at the lower elevation edges are experiencing earlier snowmelt and higher temperatures, which force them to adapt to the new conditions by modifying their phenology. In this context, advancing the onset of flowering and seed germination times are crucial to ensure reproductive success and increase seedling survival prior to summer drought. Assisted gene flow may bring adaptive alleles and increase genetic diversity that can help throughout ontogeny. The main aim of this work is to assess the effects that different gene flow treatments could have on the desired trait changes in marginal populations. Accordingly, we established a common garden experiment in which we assayed four different gene flow treatments between Silene ciliata Pourr. (Caryophyllaceae) populations located in similar and different elevation edges, belonging to the same and different mountains. As a control treatment, within-population crosses of low elevation edge populations were performed. The resulting seeds were sown and the germination and flowering onset dates of the resulting plants recorded, as well as the seedling survival. Gene flow between populations falling on the same mountain and same elevation and gene flow from high-elevation populations from a different mountain to low-elevation populations advanced seed germination time with respect to control crosses. No significant effects of gene flow on seedling survival were found. All the gene flow treatments delayed the onset of flowering with respect to control crosses and this effect was more pronounced in among-mountain gene flows. The results of this study highlight two important issues that should be thoroughly studied before attempting to apply assisted gene flow in practical conservation situations. Firstly, among-populations gene flow can trigger different responses in crucial traits throughout the ontogeny of plant species. Secondly, the population provenance of gene flow is determinant and plays a significant role on the effects of gene flow.

Keywords: Silene, facilitated adaptation, gene flow, marginal populations, outbreeding, climate change, flowering phenology 


\section{INTRODUCTION}

Global warming is changing environmental conditions of habitats where species used to live. This climate change is forcing species to move to higher latitudes or elevations looking for adequate environments to survive (Hughes, 2000; Parmesan and Yohe, 2002; Walther et al., 2002). Another response implemented by species to deal with climate change is the adaptation to the new environmental conditions through phenotypic plasticity or evolutionary adaptation (Hoffmann and Sgró, 2011). However, some species cannot either migrate or adapt at the needed rate to cope with the effects of increasing temperatures (Hoffmann and Sgró, 2011). This situation is especially striking in alpine plant species which are particularly threatened due to limitations of dispersal, habitat availability and requirements of microclimate conditions. In this context, the rise of temperatures is a real threat to mountain species, which cannot migrate higher than the mountain summits (NoguésBravo et al., 2007; Colwell et al., 2008). Moreover, populations of high mountain species are frequently isolated from other populations, due to natural geographic barriers. This natural fragmentation may reduce the ability of species to adapt to stressing conditions, among other things, due to the lower populations' sizes, greater inbreeding loads and genetic drift, and reduced gene flow between populations (Ouborg et al., 2006; Anderson et al., 2011). Thus, species that cannot migrate or adapt to the new conditions may need active conservation strategies to escape from the extinction vortex (Aitken and Whitlock, 2013; Hällfors et al., 2014).

Multiple conservation strategies have been suggested in the last decade to mitigate the effects of global warming. Among them, facilitated adaptation actions aim to increase the evolutionary resilience of the species affected by global change (e.g., Jones and Monaco, 2009; Shoo et al., 2013; van Oppen et al., 2015). Two approaches proposed for developing facilitated adaptation actions are the traditional Assisted Migration and the novel Assisted Gene Flow. Assisted Migration, the translocation of populations to a new suitable habitat, is nowadays the most frequently used approach but still under debate (Ricciardi and Simberloff, 2009; Hällfors et al., 2014). This action may entail some ecological risks (e.g., disease transmission, competitive exclusion, pollination and dispersal failure, etc.) for the assisted population and the new hosting habitat (Loss et al., 2011; Weeks et al., 2011; Williams and Dumroese, 2013). Assisted Gene Flow, the movement of gametes from populations adapted to the changed environment to populations threatened by new conditions, has recently emerged as a less hazardous alternative to manage plant populations or species in the verge of extinction (Aitken and Whitlock, 2013; Whiteley et al., 2015). In this context, gene flow has been proposed to overcome the maladaptation to climate warming in trees (Aitken and Bemmels, 2016) and proved to be a valuable tool for the genetic rescue of small populations suffering inbreeding depression (Frankham, 2015). However, gene flow effects on the adaptive potential of recipient populations are closely related to the specific environmental conditions of the original and recipient populations. In this sense, Morente-López et al. (2020a) showed that gene flow between marginal populations that share similar environmental conditions increase genetic diversity and provide adaptive alleles. Other studies point to a reduction of fitness in marginal populations due to the incorporation of maladapted alleles from optimal populations (Dawson et al., 2010; Fedorka et al., 2012). On the contrary, Bontrager and Angert (2019) reported that gene flow from a warmer optimal population provided better adaptive response in a cooler marginal population in a temperature increase scenario.

In essence, the potential pros and cons of assisted gene flow have yet to be ground-proved in natural populations under contrasting situations to gain insight on the applicability of this approach. Also, it is important to measure the effects of gene flow on different traits throughout the ontogeny and assess whether the same gene flow can produce contrasting fitness effects on different life stages (Angert et al., 2008; Morente-López et al., 2020a). This is crucial because the outcome of a conservation action would depend on the overall response of the different fitness components measured.

Adjusting plant phenology through assisted gene flow actions can be an alternative conservation strategy for alpine plant populations that face the consequences of climate warming. The long snow cover duration results in a short period for alpine plants to grow and reproduce before the early frosts of autumn (Stinson, 2004; Molau et al., 2005; Sedlacek et al., 2015). This period is even shorter in the Mediterranean Alpine ecosystems where the soil moisture availability is lower due to high temperatures and reduced rainfall in spring and summer (Giménez-Benavides et al., 2007a, 2018). Under seasonal variation, the germination timing is crucial for the subsequent seedling survival (Baskin and Baskin, 1998; Shimono and Kudo, 2003). Moreover, germination and seedling survival are highly affected by summer drought conditions in the Mediterranean mountain species (Cochrane et al., 2014; Giménez-Benavides et al., 2018). An early germination makes possible a growth of seedling roots deep enough to extract soil water and survive the summer drought. Alpine plants are expected to reduce the prefloration interval (number of days from emergence date to full flowering) to take advantage of the moist soil duration in an increasing temperatures scenario (Stinson, 2004; Hülber et al., 2010). However, earlier flowering may cause flower damages in a context of snow cover reduction due to higher temperatures and the subsequent higher risk of late spring frosts.

Silene ciliata Pourr. (Caryophyllaceae) is an alpine plant whose southernmost locations in Europe are in central Spain. Within each mountain, populations are spread along local altitudinal ranges (from $\sim 1,800$ to $2,500 \mathrm{~m}$ ). Lower elevation populations are experimenting earlier snowmelt and higher temperatures than the upper populations, and are better adapted to drought stress than populations of the summit (Giménez-Benavides et al., 2007a, 2018; García-Fernández et al., 2013; MorenteLópez et al., 2020b). However, even if plants are adapted to survive under warmer conditions, they need to adjust their reproductive phenology to new conditions through phenotypic plasticity or local adaptation (Giménez-Benavides et al., 2011b, 2018). In fact, low elevation populations of S. ciliata have showed a declining trend in the number of large reproductive 
individuals and smaller plants have lower flowering probability due to summer drought (Giménez-Benavides et al., 2011a). S. ciliata high-elevation populations bloom earlier than lowelevation populations in ex situ common garden experiments because of their lower requirement of flowering cumulative temperature ( ${ }^{\circ} \mathrm{C}$ days) (Morente-López et al., 2020b). Based on this result, gene flow from high elevation populations could be expected to advance the flowering time in low elevation populations. If so, early bloom may entail in situ an increase of the flowering period and hence reproductive performance (Giménez-Benavides et al., 2011b).

On the other hand, previous works have reported high mortality rates during early life stages of the plant (GiménezBenavides et al., 2007a; García-Fernández et al., 2012a; LaraRomero et al., 2014, 2016). These findings highlight that not only adaptations on the flowering onset are necessary, but also on the timing of germination and on seedling survival rates. Gene flow from high elevation population to low elevation population may have undesirable effects on germination and survival of the seedlings. The increase of genetic diversity due to the gene flow among populations may rise plant fitness or, on the contrary, the gene flow between isolated populations can produce a decrease in fitness due to maladaptation and outbreeding depression (Frankham et al., 2011; Aitken and Whitlock, 2013).

The main aim of this paper is to evaluate the effect of assisted gene flow coming from different origins on the adaptive potential of $S$. ciliata populations inhabiting the lower elevation edges, in response to changing environmental conditions. The distribution of the species in the study area is fragmented in three mountain ranges and comprises a steep environmental gradient. This implies that the genetic differentiation between mountains is higher than the genetic differentiation within mountains, even though populations inside the same mountain at different elevations experienced contrasted environmental conditions (Morente-López et al., 2018). This scenario allows testing the potential contrasting effects of gene flow between populations that are subject to more frequent natural gene flow between them (within mountains) versus gene flow between populations that have been isolated from each other for a longer period (among mountains). We hypothesize that the effect of the assisted gene flow will depend on the origin, and thus, on the particular environmental and historical conditions that populations experienced. We predict that gene flow from high elevation populations will induce an earlier flowering onset in lower elevation populations. However, this gene flow from high to low elevation population may bring poorly adapted genes to the more severe temperature conditions for the germination and survival stages. On the other hand, we also predict that gene flow within mountains will generate higher seedling survival rate and shorter time until germination and flowering onset in the progeny than gene flow between mountains, due to the shared evolutionary history in the former. For this purpose, we studied in a common garden the effects of the different gene flow treatments on the flowering onset, germination time and seedling survival in S. ciliata plants. Specifically, we aim to answer the following questions: (i) Can gene flow between populations advance flowering onset? (ii) What are the consequences of between population gene flow on germination and seedling survival? (iii) Do the pros overtake the cons in any of the gene flow treatments? To our knowledge, this is the first study to test whether assisted gene flow can be used to improve the viability of the marginal (low elevation) populations of an alpine plant species in response to global warming, considering different critical life stages in the same study such as seed germination, seedling survival and flowering phenology.

\section{MATERIALS AND METHODS}

\section{Study Species and Populations}

Silene ciliata is a long perennial cushion plant which inhabits a marked environmental gradient in Mediterranean alpine habitats. This species occurs in grasslands above the tree line in the Mediterranean mountain ranges of Southern Europe, from the Sistema Central in the center of the Iberian Peninsula to the Massif Central in France, the Apennines in Italy and the Balkan Peninsula (Sanz-Elorza et al., 2003; Escudero et al., 2004; Kyrkou et al., 2015) and has a late flowering period from the end of June until mid-September. Germination of S. ciliata seeds requires a previous exposure to cold temperatures, that normally takes place right after snowmelt to make the best use of soil moisture (Giménez-Benavides et al., 2005, 2007b). Summer drought is the most lethal factor for seedling survival (Giménez-Benavides et al., 2007b). Flowering onset initiates after snowmelt, with lower elevation populations flowering earlier in the field but later under ex situ common garden conditions than higher elevation populations (Giménez-Benavides et al., 2011b; Morente-López et al., 2020b). Thus, higher elevation populations may have the capacity to advance flowering onset. Similar genetic differentiation patterns concerning other functional traits associated, not to elevation but, to latitudinal gradients have been observed in other Silene species (e.g., Abeli et al., 2015; Mondoni et al., 2018). S. ciliata is a self-compatible species. Xenogamic and geitonogamic hand pollination treatments induce both fruit and seed set. However, the presence of a pronounced protandry limits passive autogamy (Giménez-Benavides et al., 2007b).

Study populations were chosen from the three main mountain ranges, Guadarrama, Béjar and Gredos of the Sistema Central mountain region, located in the center of the Iberian Peninsula (Figure 1A). These populations are considered to be relict because of their isolation from the rest of the populations of the species located in other mountain systems such as the Pyrenees, the Massif Central, the Apennines and the Balkan Peninsula (Tutin et al., 1964). The shortest distance between mountain ranges is approximately $52 \mathrm{~km}$ between Béjar and Gredos, whereas the greatest distance is $150 \mathrm{~km}$ between Guadarrama and Béjar. Within each mountain, plants from three populations were selected: two from the lowest edge and one from the highest edge of the altitudinal range. Low elevation populations are located between 1,850 and 2,000 $\mathrm{m}$ a.s.l., while high elevation populations are near to the mountain summits $(2,350-2,400 \mathrm{~m}$ a.s.1.) (Table 1).

In spite of the short distance existing between high and low elevation populations within each mountain, plants inhabiting 


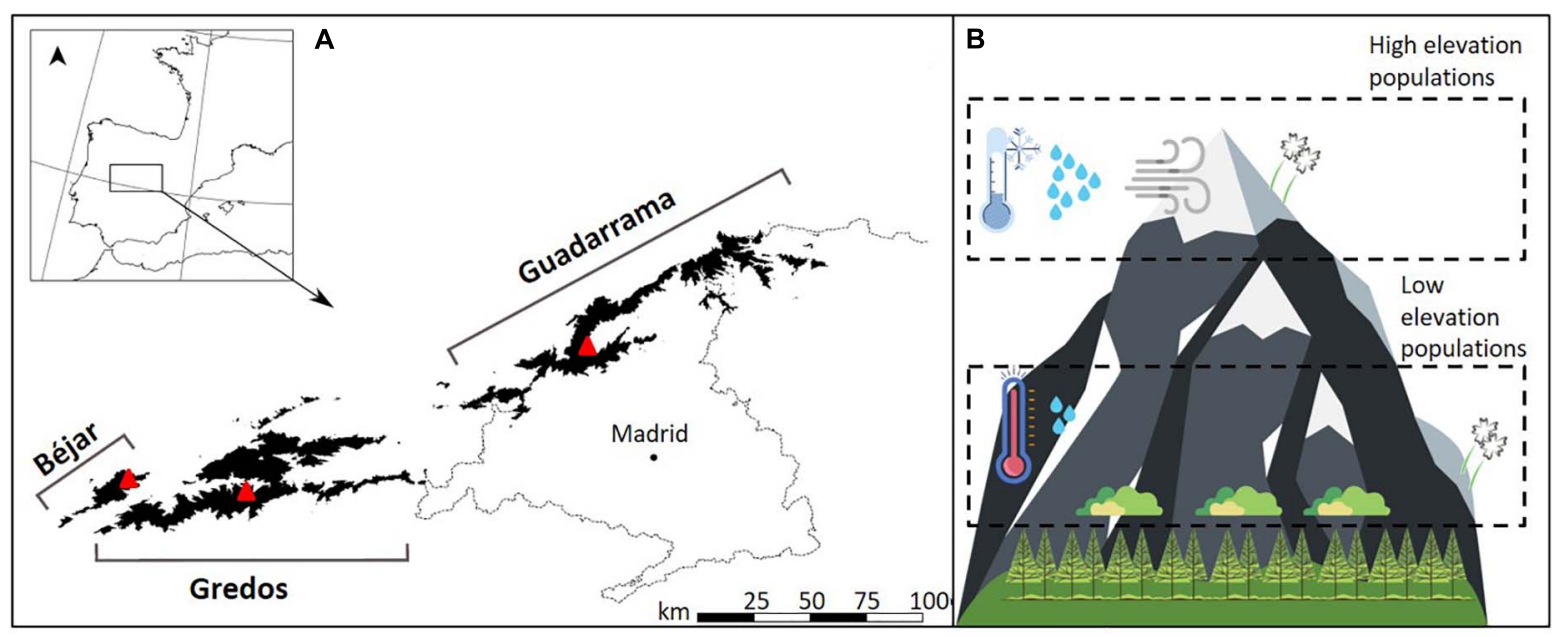

FIGURE 1 | Location and conditions experienced by Silene ciliata populations at the Sistema Central mountain region in the Central Spain. (A) Guadarrama, Béjar and Gredos constitute the three main mountain ranges. Each red triangle denotes the three sample sites (two low elevation populations and one high elevation population) within each mountain range. Black shades denote the areas above 1,500 m a.s.l. (B) Populations occur along an elevation gradient from the low edge at the timberline to the high edge at the mountain peaks. Environmental conditions are warmer, drier and less windy at the low elevation populations.

TABLE 1 | Location and elevation classification of the populations.

\begin{tabular}{|c|c|c|c|c|c|c|}
\hline Mountain range & Population & Pop. ID & m a.s.l. & Elevation class & Latitude & Longitude \\
\hline \multirow[t]{3}{*}{ Guadarrama } & Najarra baja & NAJ & 1,850 & Low & $40^{\circ} 49^{\prime} 23.46^{\prime \prime} \mathrm{N}$ & $3^{\circ} 49^{\prime} 52.53^{\prime \prime} \mathrm{W}$ \\
\hline & Morrena Peñalara & MOR & 1,980 & Low & $40^{\circ} 50^{\prime} 11.82^{\prime \prime} \mathrm{N}$ & $3^{\circ} 57^{\prime} 0.91^{\prime \prime} \mathrm{W}$ \\
\hline & Pico Peñalara & PEN & 2,400 & High & $40^{\circ} 51^{\prime} 2.11^{\prime \prime} \mathrm{N}$ & $3^{\circ} 57^{\prime} 24.02^{\prime \prime} \mathrm{W}$ \\
\hline \multirow[t]{3}{*}{ Gredos } & El Sestil & SES & 1,900 & Low & $40^{\circ} 16^{\prime} 24.45^{\prime \prime} \mathrm{N}$ & $5^{\circ} 14^{\prime} 54.93^{\prime \prime} \mathrm{W}$ \\
\hline & Los Campanarios & CAM & 2,000 & Low & $40^{\circ} 15^{\prime} 42.63^{\prime \prime} \mathrm{N}$ & $5^{\circ} 12^{\prime} 55.74^{\prime \prime} \mathrm{W}$ \\
\hline & Altos del Morezón & ZON & 2,380 & High & $40^{\circ} 14^{\prime} 57.5^{\prime \prime} \mathrm{N}$ & $5^{\circ} 16^{\prime} 8.3^{\prime \prime} \mathrm{W}$ \\
\hline \multirow[t]{3}{*}{ Béjar } & Las Cimeras & RUI & 2,000 & Low & $40^{\circ} 21^{\prime} 7.03^{\prime \prime} \mathrm{N}$ & $5^{\circ} 40^{\prime} 59.71^{\prime \prime} \mathrm{W}$ \\
\hline & Pico El Águila & AGl & 1,950 & Low & $40^{\circ} 21^{\prime} 12.36^{\prime \prime} \mathrm{N}$ & $5^{\circ} 41^{\prime} 46.52^{\prime \prime} \mathrm{W}$ \\
\hline & Canchal Negro & NEG & 2,360 & High & $40^{\circ} 20^{\prime} 19.97^{\prime \prime} \mathrm{N}$ & $5^{\circ} 41^{\prime} 22.27^{\prime \prime} \mathrm{W}$ \\
\hline
\end{tabular}

these two sites experience contrasting biotic and abiotic conditions (Figure 1B). Low elevation populations are located next to the timberline (Pinus sylvestris) in an interspersed shurbpasture matrix (Cytisus oromediterraneus, Juniperus communis, and Festuca curvifolia). High elevation populations share the habitat only with pastures of F. curvifolia and Nardus stricta. Low elevation sites are $2.9^{\circ} \mathrm{C}$ warmer during the reproductive season than high elevation populations, have higher minimum temperatures, less wind and the snow cover remains for a significantly shorter period of time (Giménez-Benavides et al., 2007a,b; Morente-López et al., 2020b). These environmental differences have been documented to create selective pressures acting on genetically based phenotypic differentiation and adaptive patterns in populations at different elevations (MorenteLópez et al., 2020a,b).

\section{Plant Collection}

At the end of the summer of 2013 we collected a minimum of 29 randomly selected plants from each of the nine populations (Figure 2A and Table 2). Collected plants were divided in a variable number of cuttings (depending on the size of the plant) to obtain a greater number of clonal individuals and potted in $0.5 \mathrm{~L}$ plastic pots with commercial potting substrate (Table 2). They were then kept in a common garden at the Universidad Rey Juan Carlos CULTIVE facility laboratory greenhouse (690 $\mathrm{m}$ a.s.l.; $40^{\circ} 20^{\prime} 02^{\prime \prime} \mathrm{N} / 3^{\circ} 52^{\prime} 59^{\prime \prime} \mathrm{W}$ ) to let them root and grow. The plants resulting from the cuttings conformed the parental generation.

\section{Gene Flow Treatments}

In the flowering season of 2014 we performed crosses within and between populations, and within and between mountains to generate five different gene flow treatments as follows (Figure 2A):

I. Control, within-population crosses in the low elevation populations (AGI, CAM, and MOR). We considered this gene flow treatment as the reference to compare the rest of the treatments, since it represents no change in the genetic composition of the populations.

II. HLWM, crosses using pollen from high elevation populations on plants from low elevation populations 
A

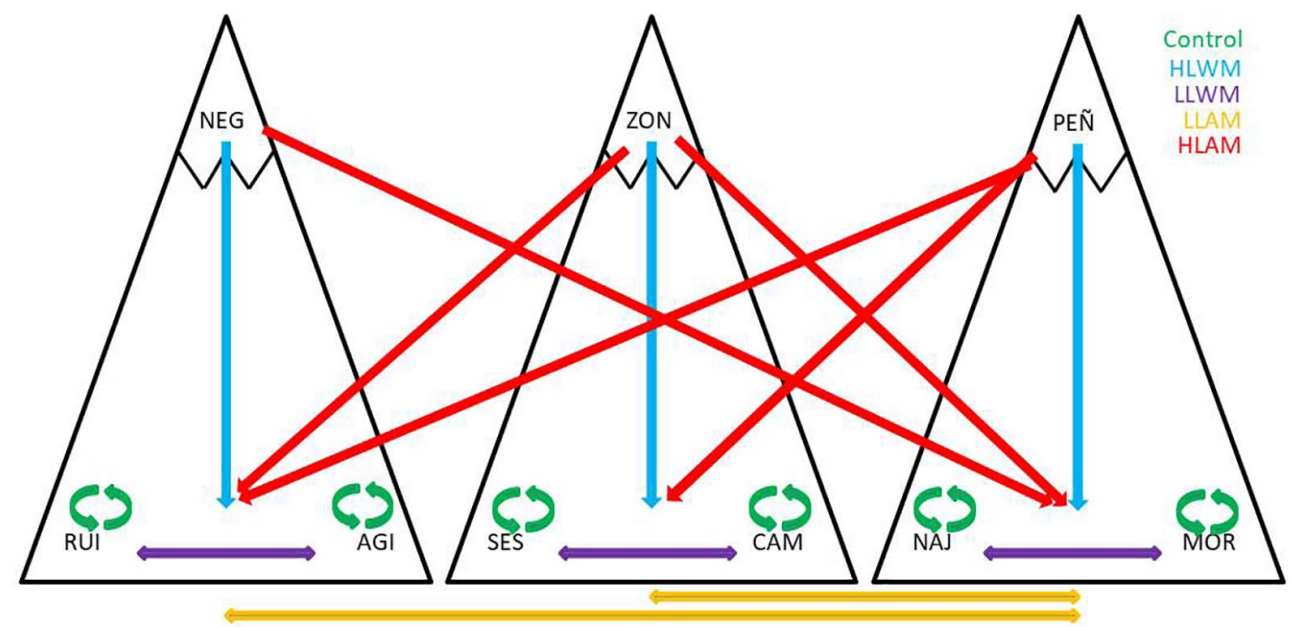

B

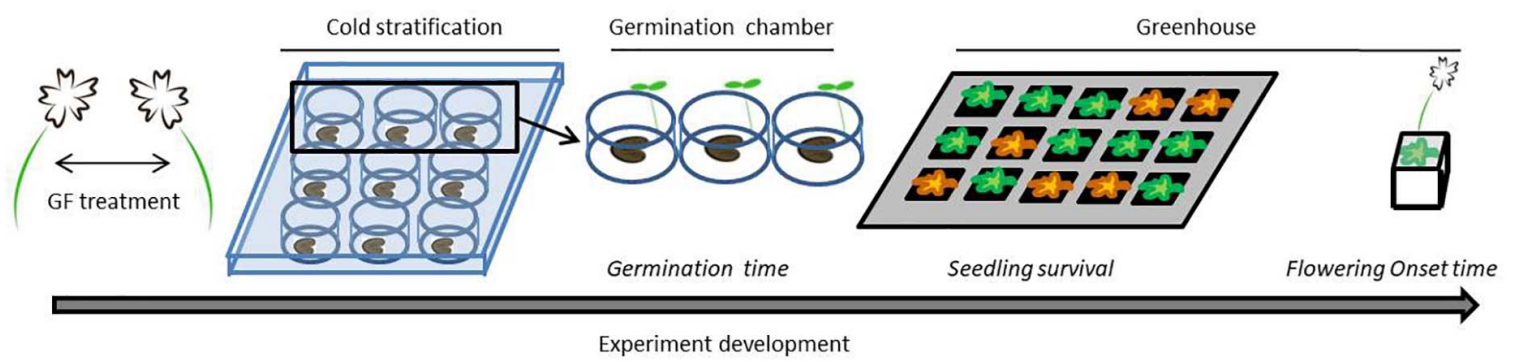

FIGURE 2 | Experimental methodology followed in the study. (A) Gene flow within and between populations from the three mountain ranges considered in this study (Béjar, Gredos, and Guadarrama). The arrow marks the direction of the pollen flow between populations. Green arrows denote the within population treatment (Control). Purple and orange arrows denote flow from low to low elevation population, within (LLWM) and among mountains (LLAM), respectively. Blue and red arrows denote flow from high to low elevation population, within (HLWM) and among mountains (HLAM), respectively. Blue, red and orange gene flows were implemented in the two low elevation populations of each mountain. Gene flow from NEG to low elevation populations of Gredos mountain range could not be performed. (B) Workflow from seed germination to flowering onset data collection. Seeds from the five gene flow treatments were deposited in multiwell plates, kept under cold stratification and then incubated in the germination chamber. Germinated seeds were first transferred to small pots where seedling survival was recorded. Four months later, plants were transferred to larger pots and flowering onset was recorded in due time.

within the same mountain. We expected that this gene flow treatment would induce earlier flowering. Moreover, it would increase genetic diversity without outbreeding depression due to gene flow from a geographically close but environmentally differentiated population from the same mountain. Seedling survival might vary depending on the outcome of potential maladaptive allele combinations vs. reduction of inbreeding depression.

III. LLWM, crosses within mountain using pollen from a low elevation population on plants from another low elevation population. We expected that this gene flow treatment would not change flowering date (gene flow from low population). Nevertheless, it would increase genetic diversity without outbreeding depression from a naturally connected and environmentally similar population from the same mountain, reducing inbreeding depression and, thereby, increasing seedling survival.

IV. LLAM, crosses using pollen from a low elevation population on plants from another low elevation population from a different mountain. We considered that this gene flow treatment would not change flowering date (gene flow from low population). Nevertheless, this gene flow would increase genetic diversity from naturally isolated (different mountain range) but environmentally similar populations. Seedling survival might vary depending on the outcome of potential outbreeding depression vs. reduction of inbreeding depression.

V. HLAM, crosses using pollen from high elevation populations on plants from low elevation populations from a different mountain range. We considered that this gene flow treatment would induce earlier flowering (gene flow from high population). Moreover, it would increase genetic diversity from naturally isolated (different mountain) and environmentally differentiated populations. In spite of a reduction of inbreeding depression, seedling survival could decrease as a result of potential outbreeding depression and the arrival of maladaptive allele combinations. 
TABLE 2 | Number of mother plants (collected in the field) and number of clonal plants (generated from cuttings) of each low elevation population. Number of seeds, seedlings and flowered plants used to measure the germination time, seedling survival and flowering onset time, respectively. The low elevation population is the plant population that received the pollen of the gene flow treatments.

\begin{tabular}{|c|c|c|c|c|c|c|}
\hline Low elevation population & No. of mother plants & No. of clonal plants & Treatment & No. of seeds & No. of seedlings & No. of flowering plants \\
\hline \multirow[t]{5}{*}{ AGl } & 46 & 79 & Control & 103 & 68 & 3 \\
\hline & & & HLWM & 119 & 87 & 27 \\
\hline & & & LLWM & 149 & 88 & NA \\
\hline & & & LLAM & 149 & 101 & 14 \\
\hline & & & HLAM & 197 & 142 & 31 \\
\hline \multirow[t]{5}{*}{$\mathrm{RUI}$} & 31 & 125 & Control & 105 & 72 & NA \\
\hline & & & HLWM & 125 & 95 & NA \\
\hline & & & LLWM & 149 & 100 & NA \\
\hline & & & LLAM & 86 & 64 & NA \\
\hline & & & HLAM & 137 & 99 & NA \\
\hline \multirow[t]{5}{*}{ MOR } & 29 & 80 & Control & 271 & 175 & 36 \\
\hline & & & HLWM & 167 & 104 & 29 \\
\hline & & & LLWM & 269 & 161 & NA \\
\hline & & & LLAM & 227 & 153 & 41 \\
\hline & & & HLAM & 223 & 139 & 42 \\
\hline \multirow[t]{5}{*}{ NAJ } & 43 & 74 & Control & 215 & 143 & NA \\
\hline & & & HLWM & 272 & 183 & NA \\
\hline & & & LLWM & 287 & 181 & NA \\
\hline & & & LLAM & 205 & 126 & NA \\
\hline & & & HLAM & 188 & 145 & NA \\
\hline \multirow[t]{5}{*}{ CAM } & 46 & 83 & Control & 211 & 137 & 6 \\
\hline & & & HLWM & 236 & 157 & 26 \\
\hline & & & LLWM & 244 & 180 & NA \\
\hline & & & LLAM & 257 & 170 & 35 \\
\hline & & & HLAM & 202 & 161 & 39 \\
\hline \multirow[t]{6}{*}{ SES } & 33 & 103 & Control & 241 & 134 & NA \\
\hline & & & HLWM & 243 & 174 & NA \\
\hline & & & LLWM & 253 & 170 & NA \\
\hline & & & LLAM & 176 & 124 & NA \\
\hline & & & HLAM & 315 & 196 & NA \\
\hline & & & Total & 6,021 & 4,029 & 329 \\
\hline
\end{tabular}

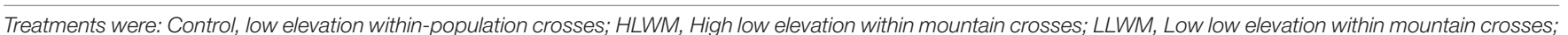

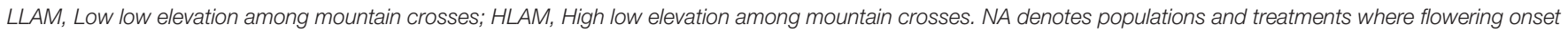
was not measured.

The experimental gene flow design was not reciprocal as it was focused on studying the effects of assisted gene flow on the marginal populations occurring at the low elevation distribution edge. Thus, the recipients of gene flow treatment were always the marginal populations as in previous study assessing similar questions (see Morente-López et al., 2020a).

\section{Cultivation and Data Collection}

In 2014, the fruits obtained from the above-mentioned crosses were collected and the seeds were counted and cleaned. 11201 seeds were subjected to a cold and wet stratification treatment to ensure a high percentage of germination (Giménez-Benavides et al., 2007a; Figure 2B). The number of obtained seeds per cross varied from 8 to 24 , with the $89.5 \%$ of the crosses having at least 24 seeds. Seeds were placed separately in multiwell plates with Whatman filter paper wetted with distilled water. Dishes were stored in a refrigerator in the dark at $1^{\circ} \mathrm{C}$ for 3 months (following Giménez-Benavides et al., 2005; Figure 2B). After the stratification process, multiwell plates with the seeds were placed in a growth chamber under a 16 - $\mathrm{h}$ light $/ 8 \mathrm{~h}$-dark regime at $20^{\circ} \mathrm{C}$ (Selecta Hotcold GL, Barcelona, Spain) (Figure 2B). From April 2015, germination was checked every 2 days. Seeds were considered to be germinated when they had developed a $2 \mathrm{~mm}$ radicle. Germination time was obtained counting the days from the start of the incubation to the germination day. Seedlings were transferred to $4 \times 4 \mathrm{~cm}$ pots with a commercial potting substrate enriched with NPK fertilizer and kept, for 4 months, in an ex situ common garden at the greenhouse (Figure 2B). The pots with the seedlings were randomly placed on the greenhouse bench. The survival of the obtained seedlings was recorded in 2015 just before they were transferred to $5 \mathrm{~L}$ pots with the same type of substrate to maximize the plant growth and obtain reproductive individuals (Figure 2B). Plants remained in this common garden when flowering onset was recorded. From 1 January to 30 August 2017, the date of flowering onset of the surviving plants was registered and flowering time calculated by 
counting the days between the first of January and the first flower bloom. After the first flower appeared, the maximum diameter of all individuals was measured.

Growth conditions in the greenhouse were warmer than those found in the natural populations. In the greenhouse mean temperature from May to September (the growth season) was $23.8^{\circ} \mathrm{C}$ whereas in nature it is about $15^{\circ} \mathrm{C}$ (Giménez-Benavides et al., 2007a). As a consequence of this difference, plants flowered earlier in the greenhouse compared to natural sites (Morente-López et al., 2020b). Furthermore, plants grown in the greenhouse were watered daily, whereas natural populations experience a significant summer drought (Giménez-Benavides et al., 2007a).

\section{Statistical Analysis}

In each mountain range, the flowering onset date was recorded on one of the low elevation populations. The results of the LLWM gene flow treatment were not used in the flowering onset analysis due to the low number of plants available for this treatment when the experiment was performed (Figure 2). To test possible differences on the days until first bloom (onset) among gene flow treatments, Kaplan-Meier survival curve comparisons based on Cox proportional hazards regression models were used. GLMMs were applied to assess differences among treatments in germination time and seedling survival. A Poisson error distribution and a binomial distribution were used for germination time and seedling survival, respectively. In the three models, gene flow treatment was included as a fixed factor and the maternal plant population as a random factor. Plant size was included as a co-variable in the flowering onset survival curves models. All statistical analyses were performed in R. For the Kaplan-Meier survival curve analysis, we used the function coxme from package coxme (version 2.27, Therneau, 2018) which allows the analysis of mixed effects Cox models. For the GLMMs, the function glmer from the lme4 package (Bates et al., 2015) was applied, and, for the post hoc analysis, the function $g l h t$ from multcomp package (version 1.4-8, Hothorn et al., 2008).

\section{RESULTS}

\section{Germination and Seedling Survival}

The time until germination was recorded for 6021 germinated seeds. Survival rate was noted for 4029 seedlings (Table 2). Significant differences on germination time were found among gene flow treatments $\left(\mathrm{X}_{4}^{2}=127.39, P<0.001\right)$. LLWM and HLAM had shorter germination time than Control, HLWM and LLAM (Figure 3). LLAM seeds were the latest to germinate (Figure 3 ). The $\mathrm{R}^{2}$ of this model was $13.4 \%$ and the differences among treatments were, on average, approximately 1 day. There were no differences among treatments on seedling survival $\left(\mathrm{X}^{2}{ }_{4}=3.57, P<0.47, R^{2}=0.003\right)$. HLAM had the highest seedling survival and LLWM the lowest, with just a $2.4 \%$ difference between them $(84.5,84,82.73,83.47$, and $85.83 \%$ in Control, HLWM, LLWM, LLAM, and HLAM, respectively).

\section{Flowering Onset}

The flowering onset was different between gene flow treatments in the survival curve comparison $\left(\mathrm{X}^{2}{ }_{3}=39.04, P<0.001\right)$. Plants from within population crosses (Control) flowered earlier than plants from between population crosses regardless of the pollen provenance (HLWM, LLAM, and HLAM) (Figure 4). Plants from crosses between mountains (LLAM and HLAM) flowered later than plants from crosses within the same mountain (Control and HLWM).

\section{DISCUSSION}

The results of this study highlight that gene flow affects differently several crucial life history traits on S. ciliata, and that these effects depend on gene flow origin. Therefore, when considering the use of assisted gene flow, it is crucial to evaluate the various effects of gene flow treatments on the different traits along the ontogeny. Then, the pros and cons of different types of gene flow should be pondered to determine which type of gene flow will provide the greatest benefits, if any, for the survival of the endangered population.

One of the main effects of gene flow regardless of its origin is its capacity to reduce inbreeding depression. The mixed mating system of the species allows the build-up of inbreeding depression in small-sized marginal populations. Previous studies suggest that inbreeding depression plays an important role in the fitness of early life stages of S. ciliata (García-Fernández et al., 2012a).

\section{Assisted Gene Flow Effects on Germination and Seedling Survival}

LLWM (within mountain low-low elevation population crosses) and HLAM (between high and low elevation localities among mountains) significantly decreased seed germination time with respect to within-population crosses. In the natural populations of S. ciliata, germination occurs right after snowmelt; thus, plants that germinate earlier have more time to grow before the arrival of the summer drought (Giménez-Benavides et al., 2007b). LLWM and HLAM decreased the seed germination time in almost six percent with respect to within-population crosses. On the contrary, LLAM (gene flow among low elevation populations among mountains) increased the seed germination time. These results seemingly reflect an interaction between elevation and mountain origin of the pollen donor population (Figure 3). At short distances (within mountain), the gene flow that causes an advance of germination comes from the low population. However, when pollen comes from far distances (among mountains) it was high elevation gene flow that shortened the germination time. This interaction could be explained by two different mechanisms playing a role at once: genetic diversity increase and acquisition of adaptive alleles. As the HLAM gene flow came from a contrasting environment from the target low elevation population, the reduction on germination time may be related with the gain in genetic diversity and the decrease of inbreeding depression in 


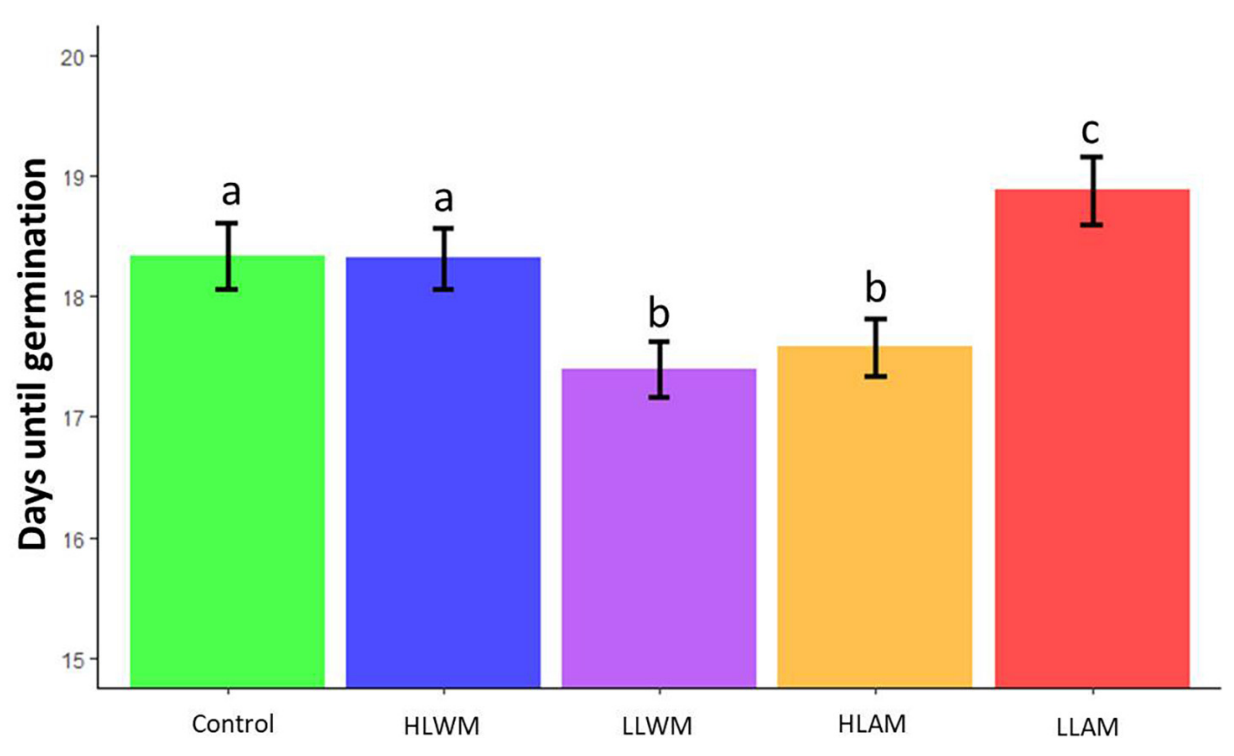

FIGURE 3 | Number of days until seed germination on different gene flow treatments. Bars denote mean \pm SE. Different letters denote significant differences among treatments. Treatments were: Control, low elevation within-population crosses; HLWM, High low elevation within mountain crosses; LLWM, Low low elevation within mountain crosses; LLAM, Low low elevation among mountain crosses; HLAM, High low elevation among mountain crosses.

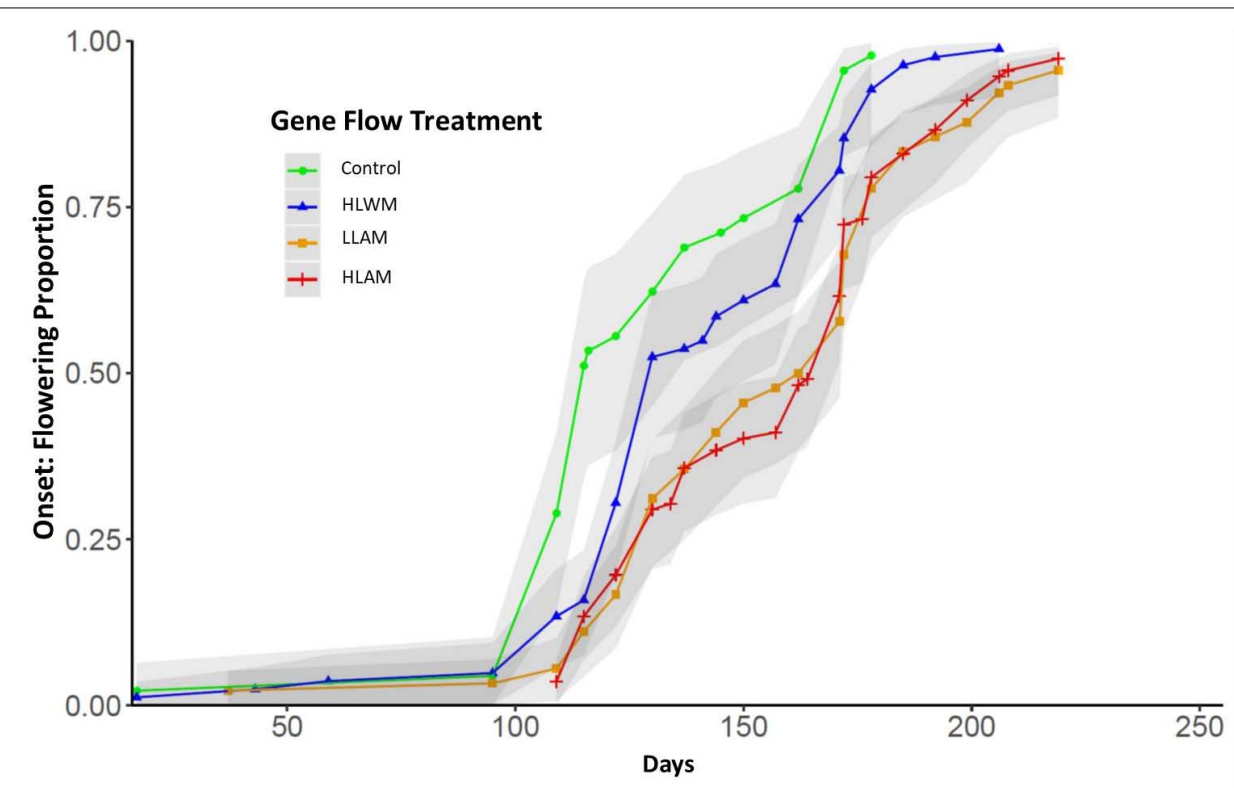

FIGURE 4 | Flowering time curves of each gene flow treatment. LLWM plants could not be included in this part of the experiment. The curves denote the accumulative increase of plants that flowered for the first time.

the target populations (Bontrager and Angert, 2019; MorenteLópez et al., 2020a). Even individuals with maladapted alleles may have a better performance in the first life stages if they benefit from an inbreeding reduction, which involves less genetic load and more vigorous seeds (Stanton and Galen, 1997; Sexton et al., 2009). The reduction in germination time by LLWM gene flow may be explained by the combined effect of genetic variation increase (gene flow from other population) and by the acquisition of adaptive alleles developed under similar environmental conditions in low elevation areas, that promotes faster germination (Sexton et al., 2011; Morente-López et al., 2020a). However, in HLWM gene flow, the net effect is null because the effect of genetic variation increase would be compensated by the effect of the incoming of maladapted alleles developed under contrasted environmental conditions.

The effects of LLAM on germination time cannot be interpreted on simple additive terms under the previous premises, and show an interaction pattern (Figure 3). A possible 
explanation is that the small size of low elevation populations may have originated significant genetic drift. This fact together with the absence of natural gene flow between mountains may have generated very different genotype complexes involved in germination that, when put together, cause a delay in germination (Frankham et al., 2017). The lack of effect of the different gene flow treatments on seedling survival could be explained by the growing conditions of the ex situ common garden. In nature, selective pressures such as summer drought negatively affect seedling survival (Giménez-Benavides et al., 2007a). In this way, in a parallel experiment performed in the natural populations, seedlings from LLWM gene flow treatment had greater survival rates than Control and HLWM (Morente-López et al., 2020a). In the common garden used in this study, seedlings did not experience the stressors that occur in natural populations (e.g., lack of soil moisture) and thus did not show differences in survival rate between treatments.

\section{Assisted Gene Flow Effects on Flowering Phenology}

Flowering time is a crucial step in the reproduction of S. ciliata (Giménez-Benavides et al., 2007b). A common garden experiment carried out with this species showed that high elevation populations bloom earlier (at lower temperatures) than low elevation populations and that this difference is genetically based (Morente-López et al., 2020b). Therefore, we expected that gene flow from high elevation populations would induce an advance in the onset of flowering time of the low elevation populations. For instance, genetic modification of the flowering time owed to natural gene flow in the context of climate change has been suggested in populations of Beta vulgaris (van Dijk and Hautekèete, 2014). Against expectations, gene flow from high elevation populations delayed flowering onset with regard to the control treatment, regardless of whether the gene flow originated from the same mountain or a different mountain (HLWM and HLAM, respectively). Furthermore, flowering onset delay was higher when gene flow originated from other mountains (LLAM and HLAM), than when it came from the same mountain (HLWM).

It is important trying to understand why the flowering onset did not change as expected following the gene flow treatments. The delays obtained in flowering onset as a result of the different gene flow treatments could be considered an expression of outbreeding depression. Outbreeding depression is a fitness reduction originated after crossing populations with somewhat distant phylogenetic lineages and/or occurring in different environments (Edmands, 2007; Frankham et al., 2011). One of the main causes of outbreeding depression is the breakup of the gene networks involved in the target trait after recombination (Aitken and Whitlock, 2013). Coadapted gene complexes may provide a phenotype than confers fitness in specific environments but interpopulation hybridization may reduce the fitness due to a disruption of coadapted genes on the gene pathways (Templeton et al., 1986; Edmands, 1999; Rawson and Burton, 2002; Ellison and Burton, 2008). Taking into account that the timing of flowering is polygenic and controlled by several gene networks (Liu et al., 2009; Amasino, 2010; Wellmer and Riechmann, 2010), the fact that the early flowering onset trait from high elevation populations was not transferred through the pollen treatment to the recipient low elevation populations suggests that the polygenic genetic control of flowering onset is not additive and that epistatic interactions may be controlling the outcome in S. ciliata (Fenster and Galloway, 2000; Montalvo and Ellstrand, 2001). In a similar way, the flowering onset delay caused by gene flow from other mountains may also derive from the interactions generated from the mixing of genetic complexes with different evolutionary histories. Intensification of the epistatic modification has been observed with increasing distance (Fenster and Galloway, 2000). Genetic differences between S. ciliata populations are higher between than within mountains, suggesting a more probable natural gene flow within mountains and gene isolation between mountain (García-Fernández et al., 2012b; Morente-López et al., 2018). Hence, the effects of epistatic interactions would be more pronounced between the populations that are more isolated and thus more genetically differentiated (i.e., LLAM) than between the populations that are naturally connected by gene flow (i.e., LLWM) (Frankham et al., 2011). Nevertheless, in most scenarios, the outbreeding depression owed to epistatic interactions is expected to be temporary and could recover in a few generations (Aitken and Whitlock, 2013). Other potential causes of outbreeding, such as, chromosomal incompatibilities and introduction of locally maladapted alleles, are discarded by the fact that our studied populations of $S$. ciliata have the same karyotype and that gene flow from low elevation populations LLAM (i.e., same environment as the recipient populations) originated the plants that were the latest to flower (Frankham et al., 2011; García-Fernández et al., 2012b; unpublished data for Gredos and Béjar mountains; Aitken and Whitlock, 2013).

One limitation of this study regarding the evaluation of gene flow effects on flowering phenology, but also on germination time and seedling survival, is the fact that the environmental conditions of the common garden experiment were different from those occurring in the low elevation edge marginal populations. Specifically, the absence of water stress in the common garden experiment does not allow to evaluate the effects of the possible rise of outbreeding depression and maladaptation that might take place under the natural environmental conditions.

\section{CONCLUDING REMARKS}

This is the first study in an alpine plant that tests the importance of gene flow provenance for implementing effective facilitated adaptation conservation strategies considering different life history traits. The effects of gene flow on the offspring should be assessed in a sufficient number of traits to ensure a positive balance of pros and cons throughout the ontogeny of the species, as it is important to evaluate the effects along the different stages of the life cycle (Aronne, 2017). In this way, it should cover not only the survival rates of the individuals but also 
their reproductive success. The results of the present work support the idea that the effects of assisted gene flow are not easily predictable and that it can cause unexpected responses in the traits aimed to be modified and also in others. Since the main functional traits of a plant are under polygenic control (e.g., Holdsworth et al., 2008; Ó'Maoiléidigh et al., 2014), the phenotypic modification of a population to improve its fitness after a change in the environmental conditions appears to be not as straightforward as we initially thought. Thus, the use of conservation strategies based on assisted gene flow should be considered with caution. Consequently, the importance of evaluating these effects prior to any conservation action in nature should be highlighted. Plants of threatened alpine populations facing a climate warming scenario will need seed germination in shorter times after snowmelt assuring in this way more time to the seedling for growing before summer drought and autumn frosts arrive. This will also help the following year to advance the onset of flowering in the next spring, right after snowmelt, to maximize seed production. Further ongoing studies on this species, which are currently testing the effects of distinct gene flow treatments on different traits in in situ common gardens near to the endangered populations should provide additional insight on the pros and cons of this potential conservation approach.

\section{DATA AVAILABILITY STATEMENT}

The datasets generated and analyzed for this study can be found in Figshare repository (10.6084/m9.figshare.13061693).

\section{REFERENCES}

Abeli, T., Orsenigo, S., Guzzon, F., Faè, M., Balestrazzi, A., Carlsson-Granér, U., et al. (2015). Geographical pattern in the response of the arctic-alpine Silene suecica (Cariophyllaceae) to the interaction between water availability and photoperiod. Ecol. Res. 30, 327-335. doi: 10.1007/s11284-014-1225-3

Aitken, S. N., and Bemmels, J. B. (2016). Time to get moving: assisted gene flow of forest trees. Evol. Appl. 9, 271-290. doi: 10.1111/eva.12293

Aitken, S. N., and Whitlock, M. C. (2013). Assisted gene flow to facilitate local adaptation to climate change. Annu. Rev. Ecol. Evol. Syst. 44, 367-388. doi: 10.1146/annurev-ecolsys-110512-135747

Amasino, R. (2010). Seasonal and developmental timing of flowering. Plant J. 61, 1001-1013. doi: 10.1111/j.1365-313X.2010.04148.x

Anderson, J. T., Willis, J. H., and Mitchell-Olds, T. (2011). Evolutionary genetics of plant adaptation. Trends Genet. 27, 258-266. doi: 10.1016/j.tig.2011. 04.001

Angert, A. L., Bradshaw, H. D., and Schemske, D. W. (2008). Using experimental evolution to investigate geographic range limits in monkeyflowers. Evolution 62, 2660-2675. doi: 10.1111/j.1558-5646.2008.00471.x

Aronne, G. (2017). Identification of bottlenecks in the plant life cycle for sustainable conservation of rare and endangered species. Front. Ecol. Evol. 5:76. doi: $10.3389 /$ fevo.2017.00076

Baskin, C. C., and Baskin, J. M. (1998). Seeds: Ecology, Biogeography, and, Evolution of Dormancy and Germination. Amsterdam: Elsevier. doi: 10.1016/C2013-000597-X

Bates, D., Maechler, M., Bolker, B., and Walker, S. (2015). Fitting linear mixed-effects models using lme4. J. Stat. Softw. 67, 1-48. doi: 10.18637/jss. v067.i01

Bontrager, M., and Angert, A. L. (2019). Gene flow improves fitness at a range edge under climate change. Evol. Lett. 3, 55-68. doi: 10.1002/evl3.91

\section{AUTHOR CONTRIBUTIONS}

JM-L, SP-B, AG-F, CL-R, and JI designed this study. JM-L, SP-B, AG-F, CL-R, MLRT, and JI collected the plants from nine populations and performed the laboratory work at CULTIVE facility. SP-B and JM-L analyzed the data. SP-B wrote the manuscript with the help of JM-L, MLRT, CL-R, AG-F, ET, and JI. All authors reviewed the manuscript and approved the final manuscript.

\section{FUNDING}

This work was supported by the projects AdAptA (CGL201233528) and EVA (CGL2016-77377-R) of the Spanish Ministry of Science and Innovation and by the Madrid Autonomous Region Government under the REMEDINAL TE-CM project.

\section{ACKNOWLEDGMENTS}

We thank the students of Universidad Rey Juan Carlos for helping in the work at CULTIVE facility laboratory greenhouse and, José Margalet for his support and technical recommendations. We also thank the staff of Parque Nacional de Guadarrama (Dirección General de Medio Ambiente, Comunidad de Madrid) and Delegación Territorial de Salamanca and Ávila (Servicio Territorial de Medio Ambiente, Junta Castilla y León) for the permission to work in the field area.

Cochrane, J. A., Hoyle, G. L., Yates, C. J., Wood, J., and Nicotra, A. B. (2014). Climate warming delays and decreases seedling emergence in a Mediterranean ecosystem. OIKOS 124, 150-160. doi: 10.1111/oik.01359

Colwell, R. K., Brehm, G., Cardelús, C. L., Gilman, A. C., and Longino, J. T. (2008). Global warming, elevation range shifts, and lowland biotic attrition in the wet tropics. Science 322, 258-261. doi: 10.1126/science.116 2547

Dawson, M. N., Grosberg, R. K., Stuart, Y. E., and Sanford, E. (2010). Population genetic analysis of a recent range expansion: mechanisms regulating the poleward range limit in the volcano barnacle Tetraclita rubescens. Mol. Ecol. 19, 1585-1605. doi: 10.1111/j.1365-294X.2010.04588.x

Edmands, S. (1999). Heterosis and outbreeding depression in interpopulation crosses spanning a wide range of divergence. Evolution 53, 1757-1768. doi: $10.2307 / 2640438$

Edmands, S. (2007). Between a rock and a hard place: evaluating the relative risks of inbreeding and outbreeding for conservation and management. Mol. Ecol. 16, 463-475. doi: 10.1111/j.1365-294X.2006.03148.x

Ellison, C. K., and Burton, R. S. (2008). Interpopulation hybrid breakdown maps to the mitochondrial genome. Evolution 62, 631-638. doi: 10.1111/j.1558-5646. 2007.00305.x

Escudero, A., Giménez-Benavides, L., Iriondo, J. M., and Rubio, A. (2004). Patch dynamics and islands of fertility in a high mountain Mediterranean community. Arct. Antarct. Alp. Res. 36, 518-527.

Fedorka, K. M., Winterhalter, W. E., Shaw, K. L., Brogan, W. R., and Mousseau, T. A. (2012). The role of gene flow asymmetry along an environmental gradient in constraining local adaptation and range expansion. J. Evol. Biol. 25, 16761685. doi: 10.1111/j.1420-9101.2012.02552.x

Fenster, C. B., and Galloway, L. F. (2000). Inbreeding and outbreeding depression in natural populations of Chamaecrista fasciculata (Fabaceae). Conserv. Biol. 14, 1406-1412. doi: 10.1046/j.1523-1739.2000.99234.x 
Frankham, R. (2015). Genetic rescue of small inbred populations: meta-analysis reveals large and consistent benefits of gene flow. Mol. Ecol. 24, 2610-2618. doi: $10.1111 /$ mec.13139

Frankham, R., Ballou, J. D., Eldridge, M. D. B., Lacy, R. C., Ralls, K., Dudash, M. R., et al. (2011). Predicción de la depresión por exogámica. Conserv. Biol. 25, 465-475. doi: 10.1111/j.1523-1739.2011.01662.x

Frankham, R., Ballou, J. D., Ralls, K., Eldridge, M. D., Dudash, M. R., Fenster, C. B., et al. (2017). "Outbreeding depression is uncommon and predictable," in Genetic Management of Fragmented Animal and Plant Populations, eds R. Frankham, J. D. Ballou, K. Ralls, M. D. Eldridge, M. R. Dudash, C. B. Fenster, et al. (Oxford: Oxford University Press), 135-155.

García-Fernández, A., Iriondo, J. M., Bartels, D., and Escudero, A. (2013). Response to artificial drying until drought-induced death in different elevation populations of a high-mountain plant. Plant Biol. 15, 93-100. doi: 10.1111/j. 1438-8677.2012.00638.x

García-Fernández, A., Iriondo, J. M., and Escudero, A. (2012a). Inbreeding at the edge: does inbreeding depression increase under more stressful conditions? OIKOS 121, 1435-1445. doi: 10.1111/j.1600-0706.2011.20219.x

García-Fernández, A., Iriondo, J. M., Vallès, J., Orellana, J., and Escudero, A. (2012b). Ploidy level and genome size of locally adapted populations of Silene ciliata across an altitudinal gradient. Plant Syst. Evol. 298, 139-146. doi: 10. 1007/s00606-011-0530-3

Giménez-Benavides, L., Albert, M. J., Iriondo, J. M., and Escudero, A. (2011a). Demographic processes of upward range contraction in a long-lived Mediterranean high mountain plant. Ecography 34, 85-93. doi: 10.1111/j.16000587.2010.06250.x

Giménez-Benavides, L., Escudero, A., García-Camacho, R., García-Fernández, A., Iriondo, J. M., Lara-Romero, C., et al. (2018). How does climate change affect regeneration of Mediterranean high-mountain plants? An integration and synthesis of current knowledge. Plant Biol. 20, 50-62. doi: 10.1111/plb.12643

Giménez-Benavides, L., Escudero, A., and Iriondo, J. M. (2007a). Local adaptation enhances seedling recruitment along an altitudinal gradient in a high mountain Mediterranean plant. Ann. Bot. 99, 723-734. doi: 10.1093/aob/mcm007

Giménez-Benavides, L., Escudero, A., and Iriondo, J. M. (2007b). Reproductive limits of a late-flowering high-mountain Mediterranean plant along an elevational climate gradient. New Phytol. 173, 367-382. doi: 10.1111/j.14698137.2006.01932.x

Giménez-Benavides, L., Escudero, A., and Pérez-García, F. (2005). Seed germination of high mountain Mediterranean species: altitudinal, interpopulation and interannual variability. Ecol. Res. 20, 433-444. doi: 10.1007/s11284-005-0059-4

Giménez-Benavides, L., García-Camacho, R., Iriondo, J. M., and Escudero, A. (2011b). Selection on flowering time in Mediterranean high-mountain plants under global warming. Evol. Ecol. 25, 777-794. doi: 10.1007/s10682-0109440-z

Hällfors, M. H., Vaara, E. M., Hyvärinen, M., Oksanen, M., Schulman, L. E., Siipi, H., et al. (2014). Coming to terms with the concept of moving species threatened by climate change - a systematic review of the terminology and definitions. PLoS One 9:e102979. doi: 10.1371/journal.pone.0102979

Hoffmann, A. A., and Sgró, C. M. (2011). Climate change and evolutionary adaptation. Nature 470, 479-485. doi: 10.1038/nature09670

Holdsworth, M. J., Bentsink, L., and Soppe, W. J. J. (2008). Tansley review Arabidopsis seed maturation, after-ripening, dormancy and germination. New Phytol. 179, 33-54.

Hothorn, T., Bretz, F., and Westfall, P. (2008). Simultaneous inference in general parametric models. Biom. J. 50, 346-363.

Hughes, L. (2000). Biological consequences of global warming: is the signal already apparent? Trends Ecol. Evol. 15, 56-61. doi: 10.1016/S0169-5347(99)01764-4

Hülber, K., Winkler, M., and Grabherr, G. (2010). Intraseasonal climate and habitat-specific variability controls the flowering phenology of high alpine plant species. Funct. Ecol. 24, 245-252. doi: 10.1111/j.1365-2435.2009.01645.x

Jones, T. A., and Monaco, T. A. (2009). A role for assisted evolution in designing native plant materials for domesticated landscapes. Front. Ecol. Environ. 7:541547. doi: $10.1890 / 080028$

Kyrkou, I., Iriondo, J. M., and García-Fernández, A. (2015). A glacial survivor of the alpine Mediterranean region: phylogenetic and phylogeographic insights into Silene ciliata Pourr. (Caryophyllaceae). PeerJ 3:e1193. doi: 10.7717/peerj. 1193
Lara-Romero, C., de la Cruz, M., Escribano-Ávila, G., García-Fernández, A., and Iriondo, J. M. (2016). What causes conspecific plant aggregation? Disentangling the role of dispersal, habitat heterogeneity and plant-plant interactions. OIKOS 125, 1304-1313. doi: 10.1111/oik.03099

Lara-Romero, C., García-Camacho, R., Escudero, A., and Iriondo, J. M. (2014). Genetic variation in flowering phenology and reproductive performance in a Mediterranean high-mountain specialist, Armeria caespitosa (Plumbaginaceae). Bot. J. Linn. Soc. 176, 384-395. doi: 10.1111/boj.12208

Liu, C., Thong, Z., and Yu, H. (2009). Coming into bloom: the specification of floral meristems. Development 136, 3379-3391. doi: 10.1242/dev.033076

Loss, S. R., Terwilliger, L. A., and Peterson, A. C. (2011). Assisted colonization: integrating conservation strategies in the face of climate change. Biol. Conserv. 144, 92-100. doi: 10.1016/j.biocon.2010.11.016

Molau, U., Nordenhäll, U., and Eriksen, B. (2005). Onset of flowering and climate variability in an alpine landscape: a 10-year study from Swedish Lapland. Am. J. Bot. 92, 422-431. doi: 10.3732/ajb.92.3.422

Mondoni, A., Orsenigo, S., Müller, J. V., Carlsson-Graner, U., Jiménez-Alfaro, B., and Abeli, T. (2018). Seed dormancy and longevity in subarctic and alpine populations of Silene suecica. Alp. Bot. 128, 71-81. doi: 10.1007/s00035-0170194-x

Montalvo, A. M., and Ellstrand, N. C. (2001). Nonlocal transplantation and outbreeding depression in the subshrub Lotus scoparius (Fabaceae). Am. J. Bot. 88, 258-269. doi: 10.2307/2657017

Morente-López, J., García, C., Lara-Romero, C., García-Fernández, A., Draper, D., and Iriondo, J. M. (2018). Geography and environment shape landscape genetics of Mediterranean alpine species Silene ciliata Poiret. (Caryophyllaceae). Front. Plant Sci. 9:1698. doi: 10.3389/fpls.2018.01698

Morente-López, J., Lara-Romero, C., García-Fernández, A., Rubio Teso, M. L., Prieto-Benítez, S., and Iriondo, J. M. (2020a). Gene flow effects on populations inhabiting marginal areas: origin matters. J. Ecol. 109, 139-153. doi: 10.1111/ 1365-2745.13455

Morente-López, J., Scheepens, J. F., Lara-Romero, C., Ruiz-Checa, R., Tabarés, P., and Iriondo, J. M. (2020b). Past selection shaped phenological differentiation among populations at contrasting elevations in a Mediterranean alpine plant. Environ. Exp. Bot. 170:103894. doi: 10.1016/j.envexpbot.2019.103894

Nogués-Bravo, D., Araújo, M. B., Errea, M. P., and Martínez-Rica, J. P. (2007). Exposure of global mountain systems to climate warming during the 21st century. Glob. Environ. Change 17, 420-428. doi: 10.1016/j.gloenvcha.2006.11. 007

ÓMaoiléidigh, D. S., Graciet, E., and Wellmer, F. (2014). Gene networks controlling Arabidopsis thaliana flower development. New Phytol. 201, 16-30. doi: $10.1111 /$ nph.12444

Ouborg, N. J., Vergeer, P., and Mix, C. (2006). The rough edges of the conservation genetics paradigm for plants. J. Ecol. 94, 1233-1248. doi: 10.1111/j.1365-2745. 2006.01167.x

Parmesan, C., and Yohe, G. (2002). A globally coherent fingerprint of climate change impacts across natural systems. Nature 421, 37-42. doi: 10.1038/ nature 01286

Rawson, P. D., and Burton, R. S. (2002). Functional coadaptation between cytochrome $\mathrm{c}$ and cytochrome $\mathrm{c}$ oxidase within allopatric populations of a marine copepod. Proc. Natl. Acad. Sci. U.S.A. 99, 12955-12958. doi: 10.1073/ pnas.202335899

Ricciardi, A., and Simberloff, D. (2009). Assisted colonization is not a viable conservation strategy. Trends Ecol. Evol. 24, 248-253. doi: 10.1016/j.tree.2008. 12.006

Sanz-Elorza, M., Dana, E. D., González, A., and Sobrino, E. (2003). Changes in the high-mountain vegetation of the central Iberian Peninsula as a probable sign of global warming. Ann. Bot. 92, 273-280. doi: 10.1093/aob/mcg130

Sedlacek, J., Wheeler, J. A., Cortés, A. J., Bossdorf, O., Hoch, G., Lexer, C., et al. (2015). The response of the alpine dwarf shrub Salix herbacea to altered snowmelt timing: lessons from a multi-site transplant experiment. PLoS One 10:e0122395. doi: 10.1371/journal.pone.0122395

Sexton, J. P., McIntyre, P. J., Angert, A. L., and Rice, K. J. (2009). Evolution and ecology of species range limits. Annu. Rev. Ecol. Evol. Syst. 40, 415-436. doi: 10.1146/annurev.ecolsys.110308.120317

Sexton, J. P., Strauss, S. Y., and Rice, K. J. (2011). Gene flow increases fitness at the warm edge of a species' range. Proc. Natl. Acad. Sci. U.S.A. 108, 11704-11709. doi: 10.1073/pnas.1100404108 
Shimono, Y., and Kudo, G. (2003). Intraspecific variations in seedling emergence and survival of Potentilla matsumurae (Rosaceae) between alpine fellfield and snowbed habitats. Ann. Bot. 91, 21-29. doi: 10.1093/aob/mcg002

Shoo, L. P., Hoffmann, A. A., Garnett, S., Pressey, R. L., Williams, Y. M., Taylor, M., et al. (2013). Making decisions to conserve species under climate change. Clim. Change 119, 239-246. doi: 10.1007/s10584-013-0699-2

Stanton, M. L., and Galen, C. (1997). Life on the edge: adaptation versus environmentally mediated gene flow in the snow buttercup, Ranunculus adoneus. Am. Nat. 150, 143-178. doi: 10.1086/286061

Stinson, K. A. (2004). Natural selection favors rapid reproductive phenology in Potentilla pulcherrima (Rosaceae) at opposite ends of a subalpine snowmelt gradient. Am. J. Bot. 91, 531-539. doi: 10.3732/ajb.91.4. 531

Templeton, A. R., Hemmer, H., Mace, G., Seal, U. S., Shields, W. M., and Woodruff, D. S. (1986). Local adaptation, coadaptation, and population boundaries. Zoo Biol. 5, 115-125. doi: 10.1002/zoo.1430050206

Therneau, T. M. (2018). Coxme: Mixed Effects Cox Models. R Package Version 2, $2-7$.

Tutin, T. G., Heywood, V. H., Burges, N. A., Valentine, D. H., Walters, S. M., and Webb, D. A. (1964). Flora Europaea. Cambridge: Cambridge University Press.

van Dijk, H., and Hautekèete, N. C. (2014). Evidence of genetic change in the flowering phenology of sea beets along a latitudinal cline within two decades. J. Evol. Biol. 27, 1572-1581. doi: 10.1111/jeb.12 410

van Oppen, M. J. H., Oliver, J. K., Putnam, H. M., and Gates, R. D. (2015). Building coral reef resilience through assisted evolution. Proc. Natl. Acad. Sci. U.S.A. 112, 2307-2313. doi: 10.1073/pnas.1422301112
Walther, G., Post, E., Convey, P., Menzel, A., Parmesan, C., Beebee, T. J. C., et al. (2002). Ecological responses to recent climate change. Nature 416, 389-395. doi: $10.1038 / 416389$ a

Weeks, A. R., Sgro, C. M., Young, A. G., Frankham, R., Mitchell, N. J., Miller, K. A., et al. (2011). Assessing the benefits and risks of translocations in changing environments: a genetic perspective. Evol. Appl. 4, 709-725. doi: 10.1111/j.17524571.2011.00192.x

Wellmer, F., and Riechmann, J. L. (2010). Gene networks controlling the initiation of flower development. Trends Genet. 26, 519-527. doi: 10.1016/j.tig.2010.09. 001

Whiteley, A. R., Fitzpatrick, S. W., Funk, W. C., and Tallmon, D. A. (2015). Genetic rescue to the rescue. Trends Ecol. Evol. 30, 42-49. doi: 10.1016/j.tree.2014.10. 009

Williams, M. I., and Dumroese, R. K. (2013). Preparing for climate change: forestry and assisted migration. J. For. 111, 287-297. doi: 10.5849/jof.13-016

Conflict of Interest: The authors declare that the research was conducted in the absence of any commercial or financial relationships that could be construed as a potential conflict of interest.

Copyright (C) 2021 Prieto-Benitez, Morente-López, Rubio Teso, Lara-Romero, GarcíaFernández, Torres and Iriondo. This is an open-access article distributed under the terms of the Creative Commons Attribution License (CC BY). The use, distribution or reproduction in other forums is permitted, provided the original author(s) and the copyright owner(s) are credited and that the original publication in this journal is cited, in accordance with accepted academic practice. No use, distribution or reproduction is permitted which does not comply with these terms. 